seemingly represents a further ossification of the "being a hard worker" mechanism that allowed her to push away the horrors and the depression after the flood. In her memories of the event, she is a caretaker guarding the family. This trait too only solidifies, as she now worries over her parents, her husband, and sometimes his relatives. Anxiety is poorly contained and death imagery is ever present in her dreams. Martha's watchfulness for the next disaster assumes near-psychotic proportions in her visions and premonitions, which seem clearly to recapitulate fragments of the flood experience. By and large, however, the extreme rigidity does safeguard the integrity of Martha's personality, with no overt breakdowns and only occasional breakthroughs of more intense anxiety and depression. Of note is Martha's eagerness to talk to the interviewers about the flood and the freshness of the associated affect. Her unfortunate guilt for years has kept her isolated from other family members during their frequent discussions of the flood, and perhaps, thereby precluded her potential for better integrating the experience.

For all four of these survivors, the family's response to the flood and its aftermath as reflected in their 1990 narrative accounts, appear closely tied to the evolution of the adaptive patterns which subsequently emerged. Helen felt protected; she now feels trusting and secure. Henry watched his father, both his grief and his determination, and he identified. Martha's parents were remote; she was the look-out then and still is. Rose's family nearly drowned, and now she barely treads water. These findings would seem to correlate with earlier Buffalo Creek studies that demonstrated psychopathology in the children to be significantly related to parental psychopathology (Gleser et al, 1981).

In addition, we might consider viewing our subjects' 1990 descriptions of their family's 1972 flood responses as "early memories" in the clinical sense. From this perspective, these memories as well as the entire 90 -minute interviews from which they are drawn, would be seen as condensations, the unraveling of which might reveal rich information about the children's experience of their family throughout their early development and the internalizations that took place. We might even wonder how often a family's response to trauma as experienced and later remembered might serve as a "psychodynamic snapshot" which captures crucial aspects of the family's influence on the child's development and internalizations. Further elucidation of the significance of these memories of the family's trauma response and of the other "clinical impressions" gleaned from our interviews would require a much more intense, psychoanalytically informed investigation than was possible within the scope of this study.

A final note in our considerations of the evolution of our subjects' coping responses into stable character structures: all of the subjects that we have described were adolescents at the time of the flood (except for Rose who was 10 years old). We might question whether the adolescent period of development is a particularly sensitive time for such transformation from coping response to character structure. Such questions are consistent with Peter Blos's observations that the central developmental task of the late adolescent period is character consolidation, which includes the automatization of idiosyncratic ways of dealing with stress (1962, p. 129). Blos points out not only that the role of trauma in character formation is central, but also that it is important to look beyond post-traumatic symptoms to post-traumatic meaning:

A character trait which forms slowly at the end of adolescence owes its special quality to a fixation on a particular trauma or component of a trauma ... focal traumata furnish a relentless force which propels the young adult towards a certain way of life which he comes to feel as his very own... Remnants of trauma relate the present to a dynamic past and establish that historical continuity in the ego which accounts for a sense of certainty, direction, and harmony between feeling and action (1962, p 134).

Such observations are consistent with our findings in the children of Buffalo Creek.

\section{Acknowledgment}

The authors thank Mela Dee Cunningham, Administrator of the Cincinnati Psychoanalytic Institute, for her invaluable assistance on this project.

\section{Bibliography}

Blos P: On Adolescence. Free Press, New York, 1962 Gleser CC, Green BL, Winget, CN: Quantifying interview data on psychic impairment of disaster survivors. J Nerv Ment Dis 1978;166:209-216.

Gleser CC, Green BL, Winget CN: Prolonged Psy chosocial Effects of Disaster. New York: Academic Press, 1981

Green BL, Korol MS, Grace MC, et al: Children and disaster. J Acad Child Adol Psychiat 1991; 30: $945-951$.
Green BL, Lindy JD, Grace MC, et al: Buffalo Creek survivors in the second decade. Amer J Onthopsychiat 1990;60:40-54.

Lyons JA: Post-traumatic stress disorder in children and adolescents. Developmental and Behavioral Pediatrics 1990;8:349-356.

Pynoos RS: Time and trauma. Psychoanal Study Child 1984;39:633-665.

Pynoos RS: Psychic-trauma in children and adolescents. Psychiat Clin North America 1985;8:815-835.
Terr LL: Too Scared to Cry. New York: Harper \& Row. 1990 Terr LL: Childhood traumas. Amer J Psychiat 1991;148:10-20.

Titchener JL, Kapp FT: Family and character change at Buffalo Creek. Amer J Psychiat 1976;133: 295-299.

Titchener JL, Kapp FT, Winget CN: The Buffalo Creek syndrome. In: Emergency and Disaster Management. Bowie, Maryland: Charles Press Publishers, 1976.

\title{
The 1988 Spitak Earthquake in Armenia: Implementation of a Mental Health Program and Clinical Observations
}

Armen Goenjian, $M D$

Visiting Associate Professor of Psychiatry, University of California-Los Angeles
School of Medicine, Los Angeles, California; Medical Director, Adult and Geriatric Psychiatry, Pacific Hospital, Long Beach, California USA
This presentation described an international mental health relief program for children and adults that was imple 
mented in Soviet Armenia after the 07 December 1988 Spitak earthquake. It presented:

1) The steps considered essential in the selection, preparation, and support of mental health workers for the relief work;

2) A method for screening and treating large numbers of students in their classrooms:

3) The rate of post-traumatic stress disorder and major depressive disorder of 532 victims clinically evaluated prior to entering treatment three to six months after the earthquake;

4) Clinical observations of significant psychological problems that may be overlooked in brief crisis-oriented psychotherapy; and

5) Multiple severe post-earthquake adversities that contributed to the psychological problems of the victims and delayed their recovery.

On 07 December 1988 at 11:41 hours, an earthquake with a magnitude of 6.9 (Richter Scale) struck Armenia Soviet Socialist Republic (population approximately 3.5 million). The tremor lasted about one minute. This was followed four minutes later by an aftershock with a magnitude of 5.8. The Spitak earthquake (named after the city closest to the epicenter of the earthquake) was one of the most devastating natural catastrophes of this century. It caused destruction of four major cities and 350 villages, killing at least 25,000 people according to Soviet estimates and as many as 100,000 according to European sources, and leaving 530,000 people homeless.

Initial screenings of therapists were used to identify and exclude applicants who lacked sufficient clinical experience, who were overly anxious, or expressed only research interest. Preparatory work included joint meetings of the prospective candidates with the therapists from the outreach program who previously had worked in the earthquake zone. Discussions included considerations of the psychological condition of the victims, therapeutic techniques, and transference/countertransference issues. Videotapes were viewed depicting the physical hardship of working and living in the earthquake zone and the condition of the victims In addition to providing necessary information to the therapists, these meetings enhanced the sense of unity among them.

One major goal of the mental health program was to extend mental health support and treatment to children and their families. The most effective way of working with children in their schools was to meet with the head teachers and assist them with their stress-related problems, while concomitantly introducing them to our work. After a positive relationship was established, we approached the teachers in a group setting to discuss their problems as well as those of the students, having in mind that teachers may fail to recognize the extent of psychological problems of children. Finally, we worked with the students.

Evaluations of children in their schools were carried out to identify those who needed treatment, as well as to provide the students with psychological first-aid. For those children who were more disturbed, further therapy was provided in the form of individual or group therapy, sometimes by combin- ing students from different classrooms. Approximately $75 \%$ of the total children treated in the schools received group therapy.

Of 532 individuals evaluated three to six months after the earthquake, $74 \%$ met criteria for Post-Traumatic Stress Disorder (PTSD) and 22\% for major depressive disorder. Very few of these individuals had a history of premorbid psychiatric disorders.

The issues listed were considered to have an important impact on the course of the victims' evolving psychological problems: 1) Anger and Suppression of Feelings; 2) Separation Anxiety; 3) Avoidance and Passivity; 3) Concealing the Truth from Children; 4) Survival Guilt; 5) Helplessness and Martyrdom; 6) Alcohol Abuse; 7) Grief Resolution; 8) Suicide; 9) Jealousy and Envy; and 10) Distortions.

The persistence of post-traumatic stress symptoms after the earthquake was related to the unremitting multiple post-disaster adversities that exacerbated symptoms or interfered with their resolution. These adversities included recurrent aftershocks which reactivated fears, separation of family members, relocation of families, lack of housing and crowded living conditions, for example, many families lived in "domigs" $(10 \times 15$ foot, make-shift, poorly insulated shacks), unemployment, disruption of community life and services, inadequacy of mental health services, and shortages of food, gasoline, and medical supplies due to the blockade by neighboring Azerbaijan. Finally, the undisposed debris and destroyed buildings served as constant reminders of the earthquake.

\section{Selected References}

Goenjian A: A mental health relief programme in Armenia after the 1988 earthquake: Implementation and clinical observations. Br J Psychiatry

$1993 ; 163: 230-239$

Goenjian A: Najarian LM; Pynoos RS; et al: Post-traumatic stress reactions after single and double trauma. Acla Psychiatrica Scand 1994;90: 214-221.

\section{The Los Angeles Earthquake of 1994}

\section{Robert Monserrate, BS}

Criminalist/Coordinator, Crisis Management Team, State Crime Laboratory; American Red Cross; Central Iowa Critical Incident Stress Team; Christian Relief Stress Management Team; Des Moines, Iowa USA
At 04:31 hours on 17 January 1994, an earthquake measuring 6.7 (Richter Scale) with the epicenter located in Northridge, California, violently shook homes and businesses in the Los Angeles area. The quake took its toll ranging from the total collapse of some struc- tures, to internal structural damage on others. The estimated damage totals were 57 people killed ( 22 by heart attack), approximately 10,000 injured, 25,000 people homeless, and more than [US] $\$ 20$ billion dollars in property damage. 